\title{
Flow analysis using RDDA method with actual usage in water distribution network
}

\author{
Hyundong Lee ${ }^{1 *}, \mathrm{Si}-\mathrm{Hwan} \mathrm{Choi}^{2}$ \\ ${ }^{1}$ Senior Research Fellow, Department of Land, Water and Environment Research, Korea Institute of Civil Engineering and Building \\ Technology / University of Science and Technology \\ ${ }^{2}$ Vice president, Shinwoo Engineering \\ *Corresponding author E-mail: hdlee@ kict.re.kr
}

\begin{abstract}
In the analysis of the water pipeline network, the amount of demand applied is assumed based on the valve being open 24 hours, unlike cases where water is supplied when the valve is opened and blocked when it is closed. As a result, existing analysis results and actual survey data show a lot of differences in hydraulic pressure and flow rate. Also, problems such as faulty outflow, lack of pumping capacity, low reservoir height, and failure to operate decompression facilities have been confirmed. In this paper, a real demand driven analysis method is proposed to solve these problems. First, a virtual flow control facility, a virtual low water column, and a virtual node are applied to the analytical model. In the next step, as the existing demand amount is used at the virtual node, if the water in the reservoir is below a certain level water is supplied from the flow control facility and the flow is shut off when the water level exceeds a certain level. This is a method to analyze the water pipeline network by supplying the usage amount.
\end{abstract}

Keywords: Water pipeline network, Real demand driven analysis, Actual survey data, Virtual flow control facility, Virtual node.

\section{Introduction}

In the analysis of the water pipeline network, the inputs of the demands in the nodes are entered and analyzed as the continuous supply from opened valves or faucets for 24 hours based on the demand of the corresponding customers (e.g., large customers, ordinary customers) as shown in the bold solid line in Fig. 1. In reality, however, actual customers use water by opening/closing the valves according to their purpose of use (e.g., replenishing water in a large water tank for large customers, dish washing or toilet usage for ordinary consumers) as shown by the thin line in Fig. 1; the valve remains open for about an hour during a day for ordinary customers (entry diameter: $15 \mathrm{~mm}$ ) and more or less is the same for large customers. In other words, tens of times of the demand is supplied during the supply time to the customer. In both methods, the sum of the water consumption for a day is the same. Meanwhile, the time that each customer uses water is not in the same time range - they may overlap with each other or use water in a totally different time range, resulting in a complicated form of supply. In the current analysis of demands, the demands assumed to be supplied with the valve opened for 24 hours are analyzed by entering one-tenth of the supply amount at which the valve is opened, which is considerably different from the actual flow. In a region where a large customer with a water tank are included, there is a problem in that, in the case where a large customer is supplied with water in a water tank or where the respective customers open a faucet at the same time, the city water supply fails to reach the ordinary customers.

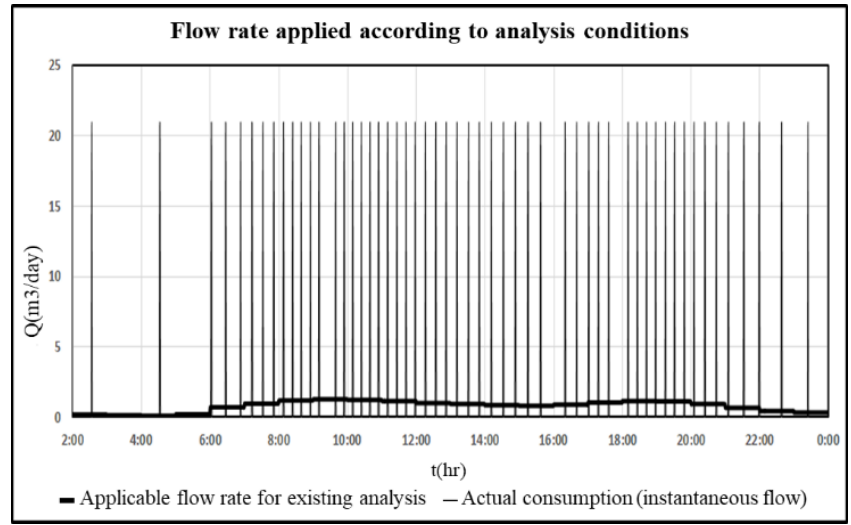

Fig. 1: Applied flow rate according to analysis conditions

\section{Relevant Research}

To alleviate the mismatch between the waterworks survey data and the pipe network analysis data, the water supply network using GIS (Geographic Information System) technology is interpreted and the technologies related to the management of the intelligent water pipeline network have been studied a lot [1] [2] [3] [4]. The existing methods assume that the valve at the nodal point is always opened, and the supply volume is one over several tenths of the actual consumption to analyze the water pipeline network according to 24-hour usage patterns. This kind of method to estimate demands is unable to analyze the flow rate and water pressure during water supply to the reservoir and instantaneous supply to ordinary customers due to frozen faucets. As for the Demand Driven Analysis (DDA) technique, which is the existing water pipeline network analysis technique, the Pressure Demand Analy- 
sis (PDA), and the Real Demand Driven Analysis (RDDA) which we propose in this thesis, the DDA technique is to calculate the head of the nodal points in the state where the supply amount of the nodal points is specified, which makes it suitable for the pipeline network analysis of normal flow with no changes in water pressure. Here, EPANET is mainly used. The water pressure at each node shall be calculated by using the continuity equation and the recurrence equation, provided that the flow rate demanded at the node can be fulfilled at any time. Abnormal conditions in which hydrological conditions change in the water pipeline network (e.g., interruption in the duct line, increase in head loss, abrupt increase in flow rate demands in the local area, etc.) may cause negative pressure at some nodes. However, from analytical results it can be deduced that the demand is maintained even if the water pressure drops close to zero. Moreover, there is another problem in that it is unable to analyze the instantaneous flow rate that occurs at the node (which is tens of times of the demand) as its analysis is based on the fact that the faucet is opened at the nodal point to supply water for 24 hours. Meanwhile, the Pressure Demand Analysis (PDA) technique is to calculate the supply amount according to the required head in the state where the head of the nodal point and supply amount are unknown. It is suitable for the pipeline network analysis of abnormal flow such as tube failures and low pressure status inside the pipe. It is possible to estimate the actual suppliable flow rate which cannot be simulated in the DDA. The relationship with the Head Outflow Relationship (HOR) should be identified based on the measured value of the nodes and the establishment of the monitoring system. Negative pressure does not occur during analysis by the PDA technique, but the numerical analysis results which are contrary to the theory can be derived according to the relations of HOR. However, this technique also has a problem in that it is unable to analyze the instantaneous flow rate that occurs at the node (which is tens of times of the demand) as its analysis is based on the fact that the faucet is opened at the nodal point to supply water for 24 hours. The Real Demand Driven Analysis (RDDA) technique proposed in this thesis aims to reduce the gap between the existing pipeline network analysis results and the actual survey results by ensuring the demand amount supplied at the nodes is similar to the actual amounts being used.

Table 1: Comparison of pipeline analysis methods

\begin{tabular}{|c|c|c|c|}
\hline Classification & $\begin{array}{c}\text { RDDA } \\
\text { (Real Demand Driv- } \\
\text { en Analysis) }\end{array}$ & $\begin{array}{l}\text { DDA } \\
\text { (Demand } \\
\text { Driven Analy- } \\
\text { sis) }\end{array}$ & $\begin{array}{c}\text { PDA } \\
\text { (Pressure De- } \\
\text { mand Analysis) }\end{array}$ \\
\hline $\begin{array}{l}\text { Analysis } \\
\text { outline }\end{array}$ & $\begin{array}{l}\text { Calculate the head of } \\
\text { a nodal point by } \\
\text { applying the instan- } \\
\text { taneous flow rate of } \\
\text { the nodal point by } \\
\text { pipe diameter only } \\
\text { to the opening time } \\
\text { of the valve. }\end{array}$ & $\begin{array}{l}\text { Calculate the } \\
\text { head of a } \\
\text { nodal point } \\
\text { with the sup- } \\
\text { ply amount by } \\
\text { the nodal point } \\
\text { specified. }\end{array}$ & $\begin{array}{l}\text { Calculate the } \\
\text { supply amount } \\
\text { according to the } \\
\text { head with the } \\
\text { head of the nodal } \\
\text { points and the } \\
\text { supply amount } \\
\text { unspecified. }\end{array}$ \\
\hline Supply time & More or less an hour & 24 hours & 24 hours \\
\hline $\begin{array}{l}\text { Supply } \\
\text { amount }\end{array}$ & $\begin{array}{l}\text { Supply the actual } \\
\text { consumption amount } \\
\text { only during the } \\
\text { supply time. }\end{array}$ & $\begin{array}{l}\text { Supply the } \\
\text { quantity de- } \\
\text { manded. }\end{array}$ & $\begin{array}{l}\text { Supply quantity } \\
\text { demanded ac- } \\
\text { cording to water } \\
\text { pressure. }\end{array}$ \\
\hline $\begin{array}{l}\text { Quantity } \\
\text { demanded }\end{array}$ & \multicolumn{3}{|c|}{$\begin{array}{l}\text { Total quantity demanded per day is the same (the sum of } \\
\text { instantaneous demand } \times 1 \text { hour, and that of the daily max- } \\
\text { imum quantity demanded } \times 24 \text { hours are the same) }\end{array}$} \\
\hline Issues & $\begin{array}{l}\text { Analytical condi- } \\
\text { tions must be as- } \\
\text { sumed, it takes time } \\
\text { to analyze and re- } \\
\text { quires a professional } \\
\text { analyst. }\end{array}$ & $\begin{array}{l}\text { It is difficult } \\
\text { (instantaneous }\end{array}$ & $\begin{array}{l}\text { perform actual } \\
\text { supply analysis. }\end{array}$ \\
\hline
\end{tabular}

\subsection{Simple pipeline analysis}

For the water pipeline network data used for the analysis, the net1.net in the Examples, an example for the EPANET water pipeline network analysis program by the United States Environmental Protection Agency, was used [5].

\subsubsection{Analysis method}

Existing analysis method (DDA). In the same way as in the example, the quantity demanded was entered on the assumption that it is continuously supplied through the valve opened according to a 24-hour pattern, and was analyzed in 1-minute intervals.

Real Demand Driven Analysis (RDDA). To realize the instantaneous flow rate in the pipeline network in the example, a virtual water tank node of the flow regulator applied only to the models having the demands by node was entered to include the device which allows the valve or the faucet to be opened and flow only during the supply time so that it can be analyzed in 1-minute intervals. Table 2 shows the data by nodes applied to the analysis.

Double the Real Demand Driven Analysis (RDDA-Double). The purpose of analysis based on actual usage (instantaneous flow) is to analyze problems in actual supply and solve problems accordingly. As a way to solve problems, what is proposed here is a method to limit the control flow of a large customer to double the amount of the quantity demanded. The input method was analyzed by entering the amount that passes the virtual water flow regulator twice the quantity demanded. It is not possible to regu- 
late the water flow at detached houses where water is supplied simply by opening the faucet, thus, the control flow rate was set to the maximum discharge rate.

Table 2: Application data by simple pipe node point

\begin{tabular}{|c|c|c|c|c|c|c|}
\hline \multirow[t]{2}{*}{$\begin{array}{c}\text { By } \\
\text { point }\end{array}$} & \multirow{2}{*}{$\begin{array}{c}\text { Daily } \\
\text { maximum } \\
\text { demand } \\
\text { (gal/min) }\end{array}$} & \multicolumn{3}{|c|}{ Water tank spec } & \multicolumn{2}{|c|}{$\begin{array}{l}\text { Flow regulator con- } \\
\text { trol flow }\end{array}$} \\
\hline & & $\begin{array}{l}\text { Diameter } \\
(\mathrm{ft})\end{array}$ & $\begin{array}{l}\text { Depth } \\
\text { of } \\
\text { water } \\
\text { (ft) }\end{array}$ & $\begin{array}{c}\text { Control } \\
\text { level } \\
(\mathrm{ft})\end{array}$ & $\begin{array}{c}\text { Max. } \\
\text { flow } \\
\text { (gal/min) }\end{array}$ & $\begin{array}{c}\text { Double } \\
\text { flow } \\
\text { (gal/min) }\end{array}$ \\
\hline 11 & 150 & 55.8 & 6.6 & $6.4 \sim 6.6$ & 5161 & 300 \\
\hline 12 & 150 & 55.8 & 6.6 & $6.4 \sim 6.6$ & 5161 & 300 \\
\hline 13 & 100 & 38.3 & 6.6 & $6.4 \sim 6.6$ & 2422 & 200 \\
\hline 21 & 150 & 55.8 & 6.6 & $6.4 \sim 6.6$ & 5161 & 300 \\
\hline 22 & 200 & 55.8 & 6.6 & $6.4 \sim 6.6$ & 5161 & 400 \\
\hline 23 & 150 & 55.8 & 6.6 & $6.4 \sim 6.6$ & 5161 & 150 \\
\hline 31 & 100 & 38.3 & 6.6 & $6.4 \sim 6.6$ & 2422 & 100 \\
\hline 32 & 100 & 38.3 & 6.6 & $6.4 \sim 6.6$ & 2422 & 100 \\
\hline $\begin{array}{c}32 \\
\text { Single- } \\
\text { use }\end{array}$ & 0.13 & 0.8 & 0.8 & $0 \sim 0.8$ & 4 & 4 \\
\hline
\end{tabular}
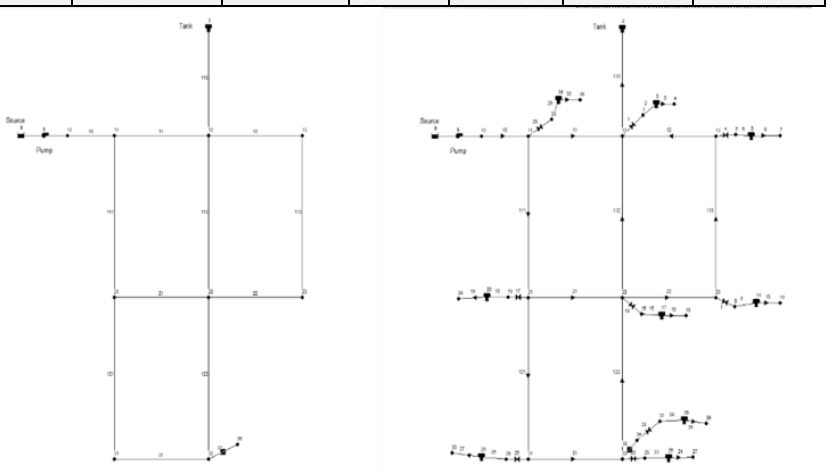

a) Block diagram of existing analysis method

b) Block diagram for analyzing with actual usage

Fig. 3. Diagram for simple pipe analysis

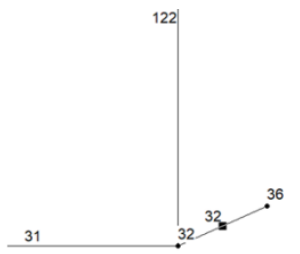

a) Block diagram of existing analysis method

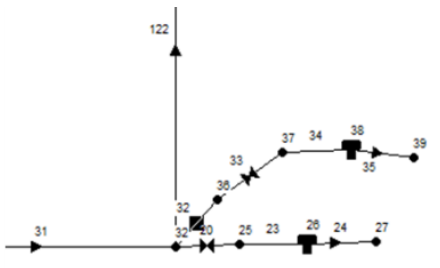

b) Block diagram for analyzing with actual usage
Fig. 4. Detail diagram for simple pipe analysis point

\subsubsection{Analysis results by pipe branch}

In Fig. 5, the upper part shows the water pressure in the $\mathrm{m}$ unit, while the lower part displays the flow rate in the $\mathrm{m} 3 /$ day unit to depict the results of the existing analysis, actual usage analysis, and double analysis for the quantity demanded on the same figure and table so as to show the difference in the results of each analysis method.

Existing analysis method (DDA). As shown in the bold lines in Table 3 and Fig. 5, the water pressure and the flow rate at nodal point 32 and pipeline 122 near the large supply area gradually changed according to the applied pattern of use, thus the water pressure change also seems moderate.

Real Demand Driven Analysis (RDDA) Method. It is the thinnest line shown in Table 3 and Fig. 5 and an analysis method designed to supply water when the valve is open and stop the water supply when the valve is closed was applied to a large supply area. As shown in Fig. 5, the analyzed water pressure and flow rate at node 32 and pipeline 122 demonstrate that a supply amount that is several tens of times more than the existing analysis method is repeated instantaneously, and the water pressure instantaneously drops to $5 \mathrm{~m}$ or less when water is supplied. Likewise, the water pressure instantaneously drops to under $5 \mathrm{~m}$ due to the influence of the large supply area and the instantaneous flow rate of the detached houses, making it difficult to supply water.

Double the Real Demand Driven Analysis (RDDA-Double). The method proposed in this thesis is to solve the problem by accurately analyzing the problems in the water pipeline network according to the real flow. This is to solve the problem with the supply by limiting the demand to twice the quantity demanded for large demand points. It is considered that limiting the supply to twice the quantity demanded shall result in a moderate change in the water pressure caused by the fluctuation of the flow rate so that the problem of supply can be addressed. It is not possible to regulate the water flow in the detached houses area where water is supplied simply by opening the faucet. At pipeline 32 and node 36 in the detached houses area in the case of instantaneous flow supply, the water pressure somewhat decreases due to the doubly limited demands in the large supply area, but it shows that it continues to maintain more than $15 \mathrm{~m}$ of pressure, which is enough for supply. The methods of limiting the supply to double the quantity demanded include the installation of bypass pipes in small diameter in the underground water tank, reduction in the main pipe and installation of a decompression device.

Table 3: Result by simple pipe analysis point

\begin{tabular}{|c|c|c|c|c|}
\hline $\begin{array}{c}\text { Analysis } \\
\text { point }\end{array}$ & $\begin{array}{c}\text { Existing } \\
\text { analysis }\end{array}$ & $\begin{array}{c}\text { Actual } \\
\text { usage anal- } \\
\text { ysis }\end{array}$ & $\begin{array}{c}\text { Double analysis } \\
\text { of the quantity } \\
\text { demanded }\end{array}$ & Remarks \\
\hline $\begin{array}{c}\text { Nodal } \\
\text { point 32 }\end{array}$ & $85.2 \sim 69.6$ & $87.0 \sim 3.1$ & $86.9 \sim 66.1$ & $\begin{array}{c}\text { Water pres- } \\
\text { sure }(\mathrm{m})\end{array}$ \\
\hline $\begin{array}{c}\text { Pipeline } \\
122\end{array}$ & $80.4 \sim 638.2$ & $\begin{array}{c}- \\
1284 \sim-\end{array}$ & $852 \sim-368$ & $\begin{array}{c}\text { Flow } \\
\text { rate }\left(\mathrm{m}^{3} / \mathrm{d}\right)\end{array}$ \\
\hline $\begin{array}{c}\text { Nodal } \\
\text { point 36 }\end{array}$ & $85.2 \sim 69.5$ & $87.0 \sim 2.7$ & $86.9 \sim 37.3$ & $\begin{array}{c}\text { Water } \mathrm{pres}- \\
\text { sure }(\mathrm{m})\end{array}$ \\
\hline $\begin{array}{c}\text { Pipeline } \\
32\end{array}$ & $0.3 \sim 1.2$ & $2.7 \sim 87$ & $0 \sim 22.3$ & $\begin{array}{c}\mathrm{Flow} \\
\text { rate }\left(\mathrm{m}^{3} / \mathrm{d}\right)\end{array}$ \\
\hline
\end{tabular}

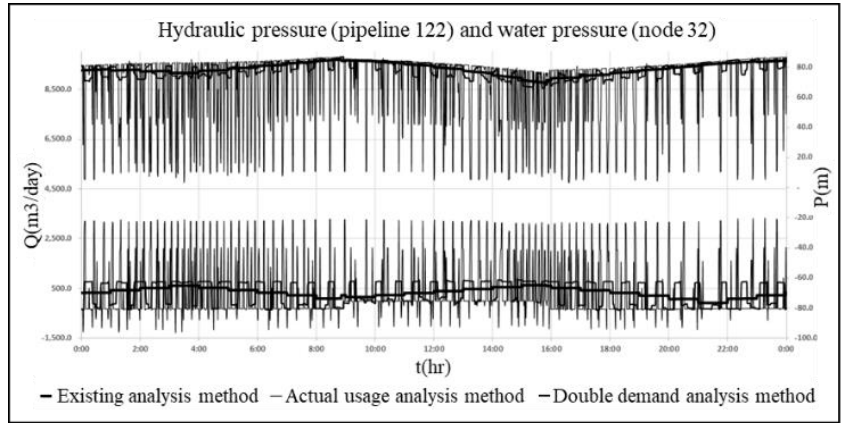

a) Water pressure and pipe flow: Large supply area

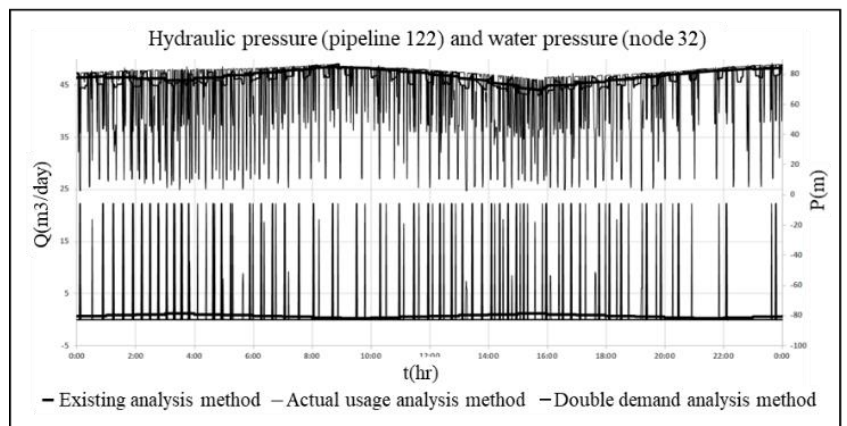

b) Water pressure and pipe flow: Detached house area

Fig. 5: Pressure and flow analysis result by simple pipe nodal point 


\subsection{Application to complex pipelines}

To ensure objectivity of the water pipeline network data used for the analysis, the net3.net in the Examples, an example for the EPANET water pipeline network analysis program by the United States Environmental Protection Agency, was used [5].

\subsubsection{Analysis method}

Table 4: Application data by complex pipe nodal point

\begin{tabular}{|c|c|c|c|c|c|c|}
\hline \multirow[b]{2}{*}{$\begin{array}{l}\text { By } \\
\text { point }\end{array}$} & \multirow[b]{2}{*}{$\begin{array}{c}\text { Quantity } \\
\text { demanded } \\
\text { (gal/min) }\end{array}$} & \multicolumn{3}{|c|}{ Water tank spec } & \multicolumn{2}{|c|}{$\begin{array}{l}\text { Flow regulator control } \\
\text { flow }\end{array}$} \\
\hline & & $\begin{array}{c}\text { Dia } \\
\text { Meter } \\
(\mathrm{ft})\end{array}$ & $\begin{array}{l}\text { Depth } \\
\text { of } \\
\text { water } \\
\text { (ft) }\end{array}$ & $\begin{array}{c}\text { Control } \\
\text { level } \\
\text { (ft) }\end{array}$ & $\begin{array}{l}\text { Maximum } \\
\text { Flow rate } \\
\text { (gal/min) }\end{array}$ & $\begin{array}{c}\text { Double } \\
\text { Flow rate } \\
\text { (gal/min) }\end{array}$ \\
\hline 101 & 189.95 & 55.8 & 6.6 & $4.6 \sim 6.6$ & 5161 & 379.9 \\
\hline 103 & 133.2 & 55.8 & 6.6 & $4.6 \sim 6.6$ & 5161 & 266.4 \\
\hline 105 & 135.37 & 55.8 & 6.6 & $4.6 \sim 6.6$ & 5161 & 270.74 \\
\hline 109 & 231.4 & 74.9 & 6.6 & $4.6 \sim 6.6$ & 9290 & 462.8 \\
\hline 111 & 141.94 & 55.8 & 6.6 & $4.6 \sim 6.6$ & 5161 & 283.88 \\
\hline 115 & 52.1 & 30.1 & 6.6 & $4.6 \sim 6.6$ & 1501 & 104.2 \\
\hline 117 & 117.71 & 55.8 & 6.6 & $4.6 \sim 6.6$ & 5161 & 235.42 \\
\hline 121 & 41.63 & 30.1 & 6.6 & $4.6 \sim 6.6$ & 1501 & 83.26 \\
\hline $\begin{array}{c}101 \\
\text { Single- } \\
\text { use }\end{array}$ & 0.13 & 0.8 & 0.8 & $0-0.8$ & 4 & 4 \\
\hline
\end{tabular}

2

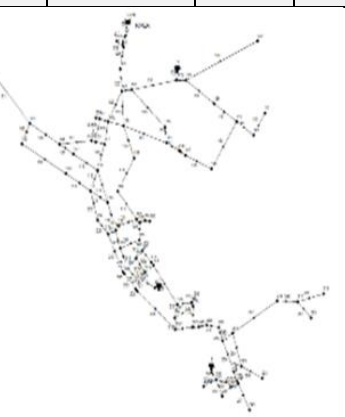

a) Block diagram of existing analysis method

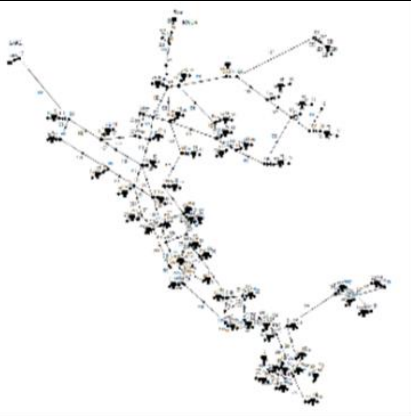

b) Block diagram for analyzing with actual usage
Fig. 6: Diagram for complex pipe analysis $\sin ^{10}$

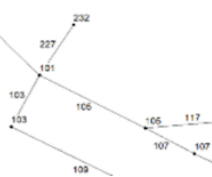

a) Block diagram of existing analysis method
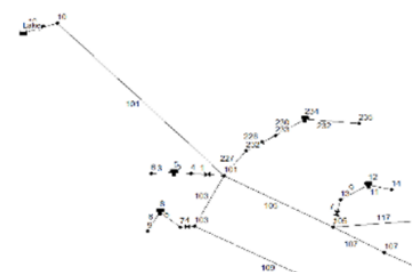
analyzing with actual usage b) Block diagram for

Fig. 7: Detail diagram for complex pipe analysis point

Existing analysis method (DDA). In the same way as the example, the quantity demanded was entered on the assumption that it is continuously supplied through the valve opened according to a 24-hour pattern, and was analyzed in 1-minute intervals.

Real Demand Driven Analysis (RDDA) Method. To realize the instantaneous flow rate in the pipeline network in the example, a virtual flow regulator water tank node applied only to the models for each node was entered to include a device which allows the valve or the faucet to be opened and flow only during the supply time so that it can be analyzed in 1-minute intervals. The data by nodes applied to the analysis are shown Table 4 . Of the total 53 nodal points, only the nine points near the analysis point shown in the figure are indicated.

Double the Real Demand Driven Analysis (RDDA-Double). The purpose of analysis based on actual usage (instantaneous flow) is to analyze problems in actual supply and solve problems accordingly. As a way to solve problems, what is proposed here is a method to limit the control flow of a large customer to double the amount of the quantity demanded. The input method was analyzed by entering the amount that passes the virtual water flow regulator twice the quantity demanded. It is not possible to regulate the water flow at detached houses where water is supplied simply by opening the faucet, thus, the control flow rate was set to the maximum discharge rate.

\subsubsection{Analysis results by pipe branch}

In Fig. 8, the upper part shows the water pressure in the $m$ unit, while the lower part displays the flow rate in the m3/day unit to depict the results of the existing analysis, actual usage analysis, and double analysis for the quantity demanded on the same figure and table so as to show the difference in the results of each analysis method.

Table 5: Results by complex pipe analysis point
\begin{tabular}{|c|c|c|c|c|}
\hline $\begin{array}{c}\text { Analysis } \\
\text { point }\end{array}$ & $\begin{array}{c}\text { Existing } \\
\text { analysis }\end{array}$ & $\begin{array}{c}\text { Real flow } \\
\text { analysis }\end{array}$ & $\begin{array}{c}\text { Double limit } \\
\text { analysis }\end{array}$ & Remarks \\
\hline $\begin{array}{c}\text { Nodal } \\
\text { point 101 }\end{array}$ & $44.5 \sim 31.2$ & $47 \sim 4.2$ & $46.3 \sim 30.0$ & $\begin{array}{c}\text { Water pres- } \\
\text { sure(m) }\end{array}$ \\
\hline $\begin{array}{c}\text { Pipeline } \\
\text { 105 }\end{array}$ & $7730 \sim-2486$ & $\begin{array}{c}13971 \sim- \\
13971\end{array}$ & $8672 \sim-3307$ & $\begin{array}{c}\text { Flow } \\
\text { rate }\left(\mathrm{m}^{3} / \mathrm{d}\right)\end{array}$ \\
\hline $\begin{array}{c}\text { Nodal } \\
\text { point 232 }\end{array}$ & $44.4 \sim 31.1$ & $53 \sim 1.0$ & $61.8 \sim 15.1$ & $\begin{array}{c}\text { Water pres- } \\
\text { sure }(\mathrm{m})\end{array}$ \\
\hline $\begin{array}{c}\text { Pipeline } \\
227\end{array}$ & $0.4 \sim 1.4$ & $0.4 \sim 23.7$ & $0 \sim 19.1$ & $\begin{array}{c}\text { Flow } \\
\text { rate }\left(\mathrm{m}^{3} / \mathrm{d}\right)\end{array}$ \\
\hline
\end{tabular}

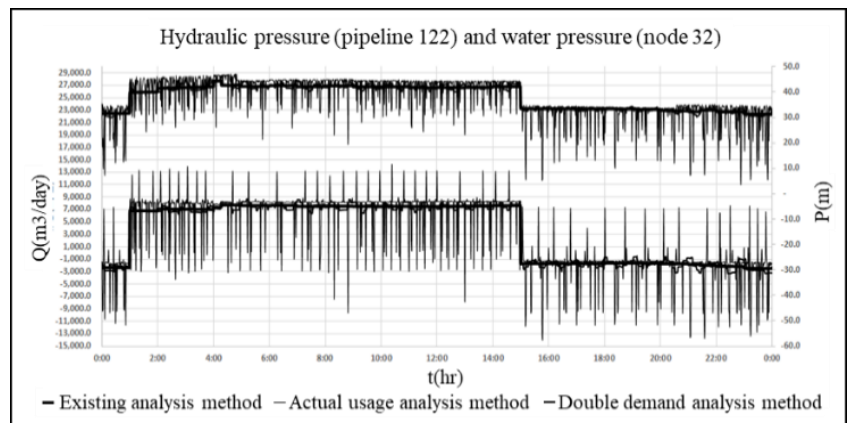

a) Water pressure and pipe flow: Large supply area

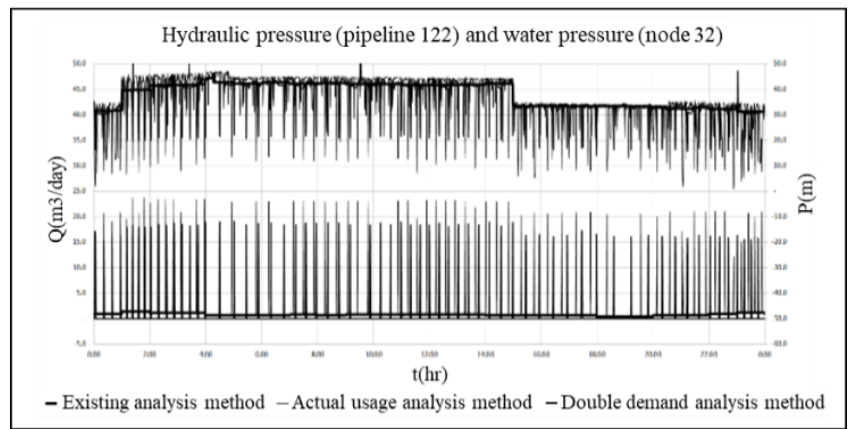

b) Water pressure and pipe flow: Detached house area

Fig. 8: Pressure and flow analysis results by complex pipe nodal point

Existing analysis method (DDA). As shown in the bold lines in Table 5 and Fig. 8, the water pressure and the flow rate at nodal point 101 and pipeline 105 near the large supply area gradually changed according to the applied pattern of use, thus the water pressure change also seems moderate.

Real Demand Driven Analysis (RDDA) Method. It is the thinnest line shown in Table 5 and Fig. 8 and an analysis method de- 
signed to supply water when the valve is open and stop the supply when the valve is closed was applied to a large supply area. As shown in Fig. 8, the analyzed water pressure and flow rate at node 101 and pipeline 105 demonstrate that a supply amount that is several tens of times more than the existing analysis method is repeated instantaneously, and the water pressure instantaneously drops to $5 \mathrm{~m}$ or less when water is supplied. Likewise, the water pressure at pipeline 227 and node 232 in the detached house area instantaneously drop to under $5 \mathrm{~m}$ due to the influence of the large supply area and the instantaneous flow rate of the detached houses, making it difficult to supply water.

Double the Real Demand Driven Analysis (RDDA-Double). The method proposed in this thesis is to solve the problem by accurately analyzing the problems in the water pipeline network according to real flow. This is to solve the problem with the supply by limiting the demand to twice the quantity demanded for large demand points. It is considered that limiting the supply to twice the quantity demanded shall result in a moderate change in the water pressure caused by the fluctuation of the flow rate so that the problem of supply can be addressed. It is not possible to regulate the water flow in the detached houses area where water is supplied simply by opening the faucet. At pipeline 227 and node 232 in the detached houses area in the case of instantaneous flow supply, the water pressure somewhat decreases due to the doubly limited demands in the large supply area, but it shows that it continues to maintain more than $15 \mathrm{~m}$ of pressure, which is enough for supply. The methods of limiting the supply to double the quantity demanded include the installation of bypass pipes in small diameter in the underground water tank, reduction in the main pipe and installation of a decompression device.

\section{Conclusion}

As only about $1 / 24$ of the actual usage is entered as the quantity demanded to be applied to the existing water pipeline network analysis method, it is difficult to analyze the poor water outflow and the drop in the water pressure of an ordinary customer while a large customer uses water. In order to address the problems with water supply such as poor water outflow, therefore, it is necessary to enter the actual usage on a per-minute basis, which is similar to the current supply status.

In the pipeline network modeling, a virtual flow regulator, a virtual water tank, and a virtual node were entered to derive the actual usage, and a flow rate similar to the actual usage (instantaneous flow) every minute could be derived according to the water level control condition. In addition, analysis using the derived actual usage every minute led to similar results to the real flow and water pressure.

Based on the results of this study, it has been confirmed that a value more similar to the real value can be derived by applying the flow rate surveyed in the field survey to the flow regulator. By applying the instantaneous flow rate, the consumption amount of large customers limited to twice the quantity demanded was analyzed and, the results confirmed that the supply of water is stable.

\section{Acknowledgement}

This work is supported by the Korea Agency for Infrastructure Technology Advancement (KAIA) grant funded by the Ministry of Land, Infrastructure and Transport (Guideline of nondestructive precision inspection and system improvement plan)

\section{References}

[1] D.I. Chang and K.H. Gang (2014), Pressure-flow relationship analysis of simulation laboratory-based nodal points for numerical analysis based on water pipeline network pressure, Korean Society of Environmental Engineers Journal, Vol.36, No.6, pp.421-428.
[2] M.S. Seo, D.G. Yu, J.H. Kim, H.D. Jeon and G.H. Chung (2009), Estimation of the importance by subsystem of the water pipeline network introduced with the effective flow concept, Journal of the Korean Society of Hazard Mitigation, Vol.9, No.6, pp.133-141.

[3] C.W. Baek, H.D. Jeon and J.H. Kim (2010), Estimation of reliability of water pipeline network using HSPDA model and ADF index, Journal of Korea Water Resources Association, Vol.43, No.2, pp.201-210.

[4] C.W. Baek, H.D. Jeon and J.H. Kim (2010), Analysis of reliability of water pipeline network using HSPDA model and distance scaling method, Journal of Korea Water Resources Association, Vol.43, No.9, pp. 769-780.

[5] https://www.epa.gov/water-research/epanet 